\title{
The Relationship between Creative Capabilities and Cultural Intelligence: Field Study of Amman's Five-Star Hotels
}

\author{
Ayad F. Altememi ${ }^{1}$, Imad A. Hassouneh ${ }^{1} \&$ Shaker Jarallah Alkshali ${ }^{2}$ \\ ${ }^{1}$ Business Administration Department, University of Petra, Amman, Jordan \\ ${ }^{2}$ Business Administration Department, Applied Science University, Amman, Jordan \\ Correspondence: Imad A. Hassouneh, Faculty of Administrative \& financial Sciences, Business Adminstration \\ Department, University of Petra, Amman, Jordan. Tel: 00962-78-6886633. E-mail: \\ emad_hassouneh@hotmail.com
}

Received: June 30, 2015

Accepted: September 30, 2015 Online Published: November 25, 2015

doi:10.5539/ijbm.v10n12p103

URL: http://dx.doi.org/10.5539/ijbm.v10n12p103

\begin{abstract}
This study aims to identify the relationship between the creative capabilities of workers in 5-star hotels in the city of Amman and their cultural intelligence. In its measurement of the creative capabilities as an independent variable, the study adopted a scale consisting of three dimensions, namely: fluency, flexibility and originality. Whereas it relied in measuring the cultural intelligence as a dependent variable, on a scale consisting of three dimensions, namely: knowledge (cognition), motivation and behavior. The study was conducted on a sample of (258) workers currently working in these hotels. The required particulars for this study were collected through a specially prepared questionnaire for this purpose after having reviewed multi previous studies. The sample was distributed according to the simple random sample mechanism. The study revealed that there is a significant positive relationship between the dimensions of creative capabilities of workers in such hotels and their cultural intelligence. The study also included a set of recommendations and mechanisms that can be applied by the managements of these hotels to tackle some aspects of the dimensions constituting the cultural intelligence of workers.
\end{abstract}

Keywords: creative capabilities, cultural intelligence, hotels, Amman

\section{Introduction}

Nowadays, the world is witnessing the phenomenon of the so-called globalization that has made the world a small village, where individuals are moving very freely from one country to another, which has led to the overlapping of different community cultures, whether for the aim of tourism and learning about the cultures of communities, or for the aim of work. All this has led to the necessity that individuals should possess the ability to deal with expatriates with different cultures coming from other societies. This requires the host communities to be willing to familiarize themselves with their guests' cultures and to employ this knowledge to get to know these guests closely. Hotels are considered one of the most business organizations which have to do with individuals with different cultures, where they are the first leg continuously frequented by these people, and this requires the employees to have the ability to adapt to them, which enhances their potential to accept others through a spirit of childhood which spontaneously accepts the common attributes among people. All that will enable workers in these hotels to acquire the personality that is able to absorb the maximum amount of information from the largest number of people welcoming them in dealing and interaction to the maximum.

\subsection{Study Importance}

The theme of this study deals with the human resources in existing 5-star hotels in Amman. The study sheds light on an utterly sensitive topic which is the extent to which workers in such hotels to interact with the customers of such business organizations who are unlike the customers of other organizations since they belong to different countries and cultures. Thus, they differ from each other in their customs, traditions and languages, the thing which gives this study its importance, whether theoretically or practically. Theoretically, the underlying importance of this study is that it conducts a review of the creative capabilities and the cultural intelligence after extensive induction of these two concepts, which researchers believe will represent the intellectual asset for researchers interested in these two concepts. Regarding the practical aspect of this study, the importance arises 
from the fact that it is one of the few studies which tackle one of the business sectors; whereas the majority of researchers in this theme focused their work on educational organizations. Furthermore, this study will bring about outcomes and recommendations that hotel managements can utilize.

\subsection{Study Problem}

The interference among cultures has become one of the inevitable phenomena, whether it's for the purpose of work or for tourism and relaxation. Hotels are one of the most business organizations that have a direct relation with this interference, either in terms of their customers who belong to different cultures and therefore have their own values, traditions, customs, language and beliefs, or in terms of their employees where in many cases they belong to different cultures as well, which requires to identify these cultures and deal with it in accordance with their objectives. But on the other hand employees need to have sufficient flexibility dealing with customers from different cultures. Therefore in this study the researchers will attempt to answer the following questions:

1) What is the level of Creative capabilities for those working in the five-star hotels in Amman?

2) What is the level of cultural intelligence of those workers?

3) Is there a significant correlation between the creative capabilities of workers and their cultural intelligence?

\subsection{Study Objectives}

This study seeks to achieve the following objectives:

1). Identify the level of creative capabilities of employees in five-star hotels in Amman.

2). Identify the level of cultural intelligence of those employees.

3). Identify whether there is a correlation between the creative capabilities of employees and their cultural intelligence.

\section{Theoretical Background}

\subsection{Creative Capabilities}

The creative thinking is considered one of the modes of thinking (Uu et al., 2012;Granot, 2011) which is divergent and original thinking that normally challenge existing, familiar and acceptable principles and does not adhere with the rules of logic, nor can the results thereof be predicted. It is more distinct than other modes of thinking (Alkaisi\&Altamimi, 2010).

The definitions mentioned by researchers to determine the meaning of creativity are multi (polysemy) and can be classified in three directions:

The first direction which views creativity as one of the styles of life where the individual utilizes his skills to identify styles that can assist him in reaching the ideas which are characterized by originality and where the individual needs to live through the stand he is going through in depth and with passivity thereby making him respond to what is agreeable with his self and thus leadto improve it, and if the individual responds to what agrees with his self, ideas different than others will be generated.

The creative individual needs to possess some qualities so as to bring about a new and unfamiliar idea such as curiosity, spontaneity, flexibility, self-criticism, originality and clarity of vision, and according to this trend, he will come to know that creativity is ideas characterized by being new, beneficial and connected with a solution for specific issues, assembling or re-arraying the known modes of knowledge in unique forms (West,2002).

The second trend views creativity as being a new yield and view creativity as being something new which can be reached through mental interaction of the individual together with the surrounding environment. According to this perception, creativity is defined as being a certain "process where the human tries, through utilizing his thinking and mental capacities as well as the surrounding different effects, to generate a new product in so far as he is concerned and his environment provided that such production is useful to the community in which he lives" (Shalley, 2004) where concentration here is on the results and on being new. However, it is not a stipulation that the landmark be at the level of the society and at the level of the individual only, in the sense that the new idea is unknown in so far as the individual but it is known in so far as the community, and may be new in respect of the individual and community. This trend concentrates on the concept that the newly born idea is useful and beneficial i.e. in the sense it satisfies the need of members of the community.

The third trend looks at the creativity as being a process through which the creative individual passes through a condition of need and unequilibrium thereby leading him to search for returning to the condition of equilibrium (Granot, 2011; Moorhead \& Griffin, 2000). Researchers are about to agree on the stages through which the 
individual goes through in the process of creativity namely: Preparation Stage, Incubation Stage, Illumination Stage and Verification Stage.

On the basis of this concept, creativity can be defined as a multi stage process wherein the activity of the individual varies from one stage to another and may also require the undertaking of more than one activity in per stage. During this process, the individual begins in identifying the issue and thence endeavor to generate the new ideas as solutions to the issue and finding support for such solutions.

Also the method of systems may be utilized to study creativity. Pursuant to this entryway, creativity can be considered to be a system comprised of (Hironymi, 2013):

1). Inputs: As represented in the internal motive which moves the individual due to his feeling of the need and unequilibrium as well as the individual's possession of some of the creative personal features such as punctuality, self-confidence, independence, spontaneity, flexibility and intelligence as well as environment's impact of creativity such as social up-bringing and extent of the group's acceptability of the individual's sharing.

2). Process: Entails the individual's going through the stages of preparation, incubation, illumination and verification.

3). Outputs: As represented in the individual's creative performance or yield and this may be in the form of a number of registered publications or patents or prizes and the like.

There are some factors which impede individuals from submitting creative ideas, and these factors can be classified to:

1). Individual Barriers: Such as fear from failure, searching for solutions by following up the rules and fear of assuming responsibility.

2). Organizational Barriers: Such as compliance with laws and instructions, unhealthy atmosphere of organization, lack of qualified administrative leadership and unfitness of the organization structure.

3). Cultural Barriers: Such as the prevailing customs, traditions and practices, economic and political situations.

Guilford (1950) believes that there is a difference between the ability for creative thinking and creative production, as he believes that the individual may enjoy sufficient mental capabilities, but he does not produce a creative production because the creative capabilities alone are not sufficient for creative production, as in addition, the suitable environmental potentials which permit the growth of such capabilities and utilization thereof must be available so as to produce a creative yield, i.e. the environment can be encouraging or discouraging to such capabilities.

The creative capabilities and constituents are not restricted to a specific group of people but rather distributed over all, and individuals vary therein amongst them in so far as the level. Creativity which can be measured with the individuals whether they produced a creative yield or otherwise (Altahir, 2005). Based on this, the organization should give to the workers the opportunity to create and discover new rules and relations with third parties.

This means that the environment has a considerable impact on building the creative personality. The original ideas are not generated from nihility but rather rely on the instinct and acquired aspects, in the sense that expertise which the individual goes through has considerable impact in his production of the original ideas.

The experiments of Torrance (1966) and Guilford (1950) comprised the following creative capabilities:

1). Fluency viz generating ideas easily i.e. tantamount of the individual's potential in quickly and easily providing a flood of ideas within a specific time unit and with respect to a specified topic, whether intellectual, pronunciation or expressive. The more fluency the individual has, the more creative production he will have.

Fluency is not a mere emanation of a series of ideas haphazardly, but rather objective ideas which the individual satisfies his multi motives. It is noted that the number of ideas is the important and not the quality of these ideas within a specific time limit consequently, the emphasis here is on the number and speed.

2). Flexibility which means the individual's ability to change the angle of his thinking while carrying out the various activities, viz the mental flexibility which is opposite to the intellectual dullness.

3). Originality which is the rare responses which transpire with certain group. The originality concentrates on the rare and unique responses. The scarcity is connected with the infrequent repetition within the group to whom the individual is affiliated. The less common the idea becomes the more originality is increased. According to this concept, originality is contra to imitation, i.e. the ideas come out from the person and is affiliated to him and 
reflects his personality.

\subsection{Cultural Intelligence}

The emergence of globalization, fading away of trade barriers and innovation in the communications mechanism and the like made it easier for all organizations throughout the world to embark into the various markets (Gubta et al., 2013).

Consequently, the personnel in such organizations are exposed to cultural contexts and unfamiliar miscellaneous work powers culturally. Such interplay between cultures pause a challenge to individuals and institutions since the cultural differences may intensify conflicts and disputes (Gubta et al., 2013). Therefore, understanding the reason which would enable some individuals to perform with better efficiency compared to others in the culturally variable stand and situations, has become more important from any other time (Dyne et al., 2012).

The cultural diversification facing the organizations has led to changing the method of thinking and work of such organizations, whilst some organizations fail to make use of the cultural diversification; others exploit it through continued adjustment in the method and manner in which business is carried out. In a heightening manner, employers acknowledge the impact of cultural changes on all aspects of an organization.

Also, the inability to understand the various cultures and adaptation therewith may cause inappropriate utilization of the language and behavior which may adversely affect the building of individual performance and organization (Gubta et al., 2013).

Researches has cumulatively shown the importance of the cultural intelligence to the leverage of performance in the cross-borders and multi-cultures cases covering manager's performance in international assignments, multi-culture negotiation potentials and effectiveness of leadership in the culturally diversified work groups (Rockstuhl et al., 2011). In addition cultural intelligence has gained an increased attention from scholars and practitioners of its importance and relevance to globalization, international business and diversified work force (Dyne et al., 2012).

The origin of cultural intelligence is due to the intelligence theories which describe it as multi-sided (Zhao et al., 2013). Also, the cultural intelligence is considered of the initial attempts and efforts that endeavored to concentrate on the characteristics and behaviors distinguishing individuals who enjoy cultural intelligence $\mathrm{v} . \mathrm{v}$ others (Gubta et al., 2013).

Cultural intelligence is defined as the capability of an individual to discover and absorb the various cultural stimuli and signals and to act accordingly in an appropriate manner in multi-cultural situations. Hence, it can be said that cultural intelligence is the competencies that can be improved through participation in education, travel and experiences of other cultures (Dyne et al., 2012).

According to (Ramalu et al., 2010) The concept of cultural intelligence denotes to the individual's capability to accommodate successfully with new and unaccustomed cultural environments and the capacity to act easily and efficiently in conditions characterized by cultural multiplicity. Therefore, cultural intelligence explains the underlying reason behind the capability of some people to act and adapt to foreign cultures beyond the comprehension of other cultures' languages.

In 2003, Early and Ang presented in their early studies the basis for the cultural intelligence structure (Johnson \&Buko, 2013), they identified it as the individual's ability to act effectively in cases and conditions of cultural multiplicity. They also conceived cultural intelligence as a multi-dimensional concept consisting of three basic elements, namely: motivation, cognition and behavior (Rockstuhl et al., 2011).

\subsubsection{Motivational Cultural Intelligence}

Motivation element as one of the cultural intelligence elements reflects the mental capacities of an individual to guide and sustain one's activity to act effectively in cases of multi-cultural status (Dyne et al., 2012). Such individuals of highly motivated cultural intelligence direct their concern towards multi-cultural situations based on their own concerns and interests (Rockstuhl et al., 2011).

Furthermore, the motivational dimension of cultural intelligence indicates one's self-motivation and the extent of adapting to new cultural environments (Zhao et al., 2013).

\subsubsection{Cognitive Cultural Intelligence}

The cultural intelligence cognitive dimension refers to general knowledge and cognitive structure regarding cultures and cultural differences (Dyne et al., 2012). Such knowledge and differences include recognition of 
behavioral and practices criteria in various cultures which are acquired by learning and personal experiences (Rockstuhl et al., 2011).

Moreover, the cultural intelligence cognitive dimension, according to (Zhao et al., 2013) refers to the individual's own knowledge regarding how a new culture is conceived and understood according to various stimuli and signals received by the individual himself. Accordingly, individuals can develop a better knowledge and understanding of other cultures and their content of behavioral patterns, systems and interactions through investigating whatever is new to them besides detaching themselves from their own cultural background.

\subsubsection{Behavioural Cultural Intelligence}

Cultural intelligence behavioral dimension reflects the capability to adjust behaviors to suit various cultural settings. Additionally, it emphasize on the ability to reflect the external manifestations and explicit procedures that would leave the other party comfortable during cultural interactions (Dyne et al., 2012).

Furthermore, cultural intelligence behavioral dimension indicates the use of appropriate verbal and non-verbal behaviors during dealing and communicating with people of various cultures. It also includes wise use of speech through culturally suitable words and expressions (Rockstuhl et al., 2011).

\section{Literature Review}

Mazur (2010) study aimed to investigate the impact of cultural diversity and its dimensions namely: (knowledge, behavior) on the practices and work of organizations. The study was applied to a random sample of (151) members of (32) various international organizations. The findings indicate the presence of behavior impact by $80 \%$ and knowledge by $20 \%$ on the practices and work of organizations. The results recommended the need to address verbal behavior of each culturally diversified member in organizations.

Alias (2011) applied study on the elementary school principals in Iraq aimed to identify cultural intelligence and its relation to social tolerance at the elementary school principals, the results showed that their level of cultural intelligence is less than average, and as for social tolerance it falls within the average. The results of the study suggests that the curriculum for all stages should include topics that contribute to raising the level of social tolerance, the provision of programs that enhances cultural awareness and tolerance with one another which close the distance among Iraqi subcultures.

Jellab (2011) study sought to explore the nature and type of correlation between emotional and cultural intelligence. Findings of the study showed that the possession of adaptive capabilities of the emotional intelligence Pave the way for possessing Cultural Intelligence capabilities. The study recommended seeking the introduction of emotional and cultural intelligence tests within the teaching validity test in Iraqi universities and institutes as well as the addition of these concepts to the curriculum in both preliminary and higher studies.

FakhrEldin (2011) study aimed to recognize the importance of cultural intelligence and the impact of its dimensions (Motivation, Knowledge, and meta-knowledge) on the staff performance at the international hospital in Egypt. The study was applied on a sample of (1297) employees from different nationalities, the results demonstrate that there is a direct positive impact of cultural intelligence on the quality of work performance; moreover the study recommended the need to conduct cultural intelligence training courses for all leaders and staff in every organization.

Hansen (2012) study examined the impact of cultural intelligence and its dimensions (Motivation, Knowledge, meta-knowledge, behavior) on sales staff in the selling process to individuals with diverse cultures from various countries. The study was implemented on (2050) employees from (72) different countries. The findings showed that there is a direct positive impact of cultural intelligence and its dimensions on sales staff performance, and that the sales staffs who possess high cultural intelligence achieves the highest sales. The results revealed the necessity of conducting studies and research on cultural intelligence and its impact on all work departments.

Alnamla (2012) study aimed to identify cultural differences confronting Saudi students in the scholarship countries. Findings indicate that the Scholarship Students encounter problems caused by cultural differences, represented by the difficulty of understanding and dealing with others. The study results revealed many recommendations, of the most important are: Decomposition of confidence, paying attention to the body language, attempting to identify other cultures.

Nafie (2012) study aimed to identify the impact of cultural intelligence on employees work performance in King Abdul-Aziz hospital in Saudi Arabia, the results revealed that cultural intelligence has a direct impact on employees performance, the study have recommended that attention needs to be given to the cultural intelligence factors and its proper application, furthermore to be considered one of the significant administrative factors. 
Kanten (2014) study examines the impact of cultural intelligence and its dimensions (Behavior, Knowledge, meta-knowledge, motivation) on the company's efficiency and employee's behavior toward customers. It was applied on a sample of (306) employees of five-star international hotels in Istanbul, the results have showed the existence of a significant impact of two dimensions (behavior, motivation) on employees behavior toward customers. The results have recommended that organizations management needs to pay more attention to employee's motivation and help them determine the specific behavior in dealing with customers.

\section{Study Hypotheses}

Ho1: There is no significant relationship between the creative capabilities components of employees (Fluency, Flexibility and Originality) in five-star hotels in Amman.

Ho2: There is no significant relationship between the employee's cultural intelligence elements (Knowledge, Motivation and Behavior) in five-star hotels in Amman.

Ho3: There is no significant relationship between employees thinking fluency and their cultural intelligence components (Knowledge, Motivation and Behavior).

Ho4: There is no significant relationship between employees thinking flexibility and their cultural intelligence components (Knowledge, Motivation and Behavior).

Ho5: There is no significant relationship between employees thinking originality and their cultural intelligence components (Knowledge, Motivation and Behavior).

\section{Methodology}

\subsection{Study Sample}

The study community consisted of all employees in the (16) five-star hotels in the Jordanian capital Amman. The sample for this study identified a number of (400) workers spread evenly on hotels representing the study community and by (25) workers for each hotel. The researchers used the simple random sample method in selecting the aforementioned number from each hotel. After distributing the questionnaires to the examinees, 258 questionnaires were handed in representing $64.5 \%$ of the total questionnaires distributed were valid for statistical analysis.

Table 1 indicates some of the personal and organizational characteristics of the employees who were the study sample. The number of male workers amounted to (183) representing (71\%) of the study sample. As for female workers, the number reached (75) females representing (29\%) of the sample. In regard of age, most of the workers within the sample were in the 30-year age category and less at a number of (120) workers representing (47\%) of the study sample. In regard of the academic achievement, the majority were B.A. holders at a number of (129) workers representing $(50 \%)$ of the sample. In respect of the service period, the majority were of the 5 -year service period and less at a number of (114) workers representing (44\%) of the sample. Finally, in regard of administrative positions, most of the workers in the study sample held supervisory positions at a number of (141) workers which represented (55\%) of the sample.

Table 1. Demographic and organizational characteristics of study sample

\begin{tabular}{|c|c|c|c|c|c|c|c|c|c|c|}
\hline \multirow{3}{*}{ Sex } & \multicolumn{5}{|l|}{ Male } & \multicolumn{5}{|c|}{ Female } \\
\hline & \multicolumn{3}{|l|}{$\mathrm{N}$} & \multicolumn{2}{|l|}{$\%$} & \multicolumn{3}{|l|}{$\mathrm{N}$} & \multicolumn{2}{|l|}{$\%$} \\
\hline & \multicolumn{3}{|l|}{183} & \multicolumn{2}{|l|}{71} & \multicolumn{3}{|l|}{75} & \multicolumn{2}{|c|}{29} \\
\hline & \multicolumn{3}{|l|}{ Less than 30 years } & \multicolumn{2}{|c|}{$30-40$ years } & \multicolumn{3}{|c|}{$41-50$ years } & \multicolumn{2}{|c|}{51 years and above } \\
\hline \multirow[t]{3}{*}{ Age } & $\mathrm{N}$ & & $\%$ & $\mathrm{~N}$ & $\%$ & $\mathrm{~N}$ & & $\%$ & $\mathrm{~N}$ & $\%$ \\
\hline & 120 & & 47 & 78 & 30 & 54 & & 21 & 6 & 2 \\
\hline & \multicolumn{3}{|l|}{ Diploma and below } & \multicolumn{4}{|c|}{ Bachelor } & \multicolumn{3}{|c|}{ Postgraduate } \\
\hline \multirow[t]{3}{*}{ Education } & $\mathrm{N}$ & & $\%$ & $\mathrm{~N}$ & & $\%$ & & $\mathrm{~N}$ & & $\%$ \\
\hline & 117 & & 45 & 129 & & 50 & & 12 & & 5 \\
\hline & \multicolumn{2}{|l|}{ Less than 5 years } & \multicolumn{2}{|c|}{$6-10$ years } & \multicolumn{2}{|c|}{$11-15$ years } & \multicolumn{2}{|c|}{$16-20$ years } & \multicolumn{2}{|c|}{21 years and above } \\
\hline \multirow[t]{3}{*}{ Experience } & $\mathrm{N}$ & $\%$ & $\mathrm{n}$ & $\%$ & $\mathrm{~N}$ & $\%$ & $\mathrm{n}$ & $\%$ & $\mathrm{~N}$ & $\%$ \\
\hline & 114 & 44 & 72 & 28 & 45 & 18 & 21 & 8 & 6 & 2 \\
\hline & \multicolumn{3}{|l|}{ Supervisor } & \multicolumn{2}{|c|}{ Section Head } & \multicolumn{3}{|c|}{ Deputy Manager } & \multicolumn{2}{|c|}{ Department Manager } \\
\hline \multirow[t]{2}{*}{ Management Level } & $\mathrm{N}$ & \multicolumn{2}{|c|}{$\%$} & $\mathrm{~N}$ & $\%$ & \multicolumn{2}{|l|}{$\mathrm{n}$} & $\%$ & $\mathrm{~N}$ & $\%$ \\
\hline & 141 & \multicolumn{2}{|c|}{55} & 72 & 28 & 27 & & 10 & 18 & 7 \\
\hline
\end{tabular}




\subsection{Study Tool}

All data required for the study were collected via a specially designed questionnaire for this objective. It consisted of three sections. The first section included the demographic information of the workers, the study sample, namely: gender, age, academic achievement, service period and administrative level. As for the second section, it included the statements designed for the creative capabilities at a number of (15) statements distributed as follows: (5) statements for fluency and the same number for flexibility and originality. As for the third section, it consisted of statements in respect of cultural intelligence at a number of (16) statements distributed as follows: (6) statements for cognition, and (5) statements for each of motivation and behavior.

\subsection{Measurements}

For measuring of the creative capabilities of the workers two measurements were used, namely (Guilford, 1950) and (Torrance, 1966), which are mostly used by researchers. They consist of three dimensions: fluency, flexibility and originality. In respect of cultural intelligence, the scale included in the study of (Ahn\&Ettner, 2013) was used and it consists of three dimensions, namely: cognition, motivation and behavior. Figure (1) refers to the variables and dimensions of the study. Internal cohesion was maintained for the statements of the toll by using Cronbach Alpha Test. Findings showed that all statements constituting the dimensions exceeded (60\%), (Sekaran, 2006) as in Table 2.

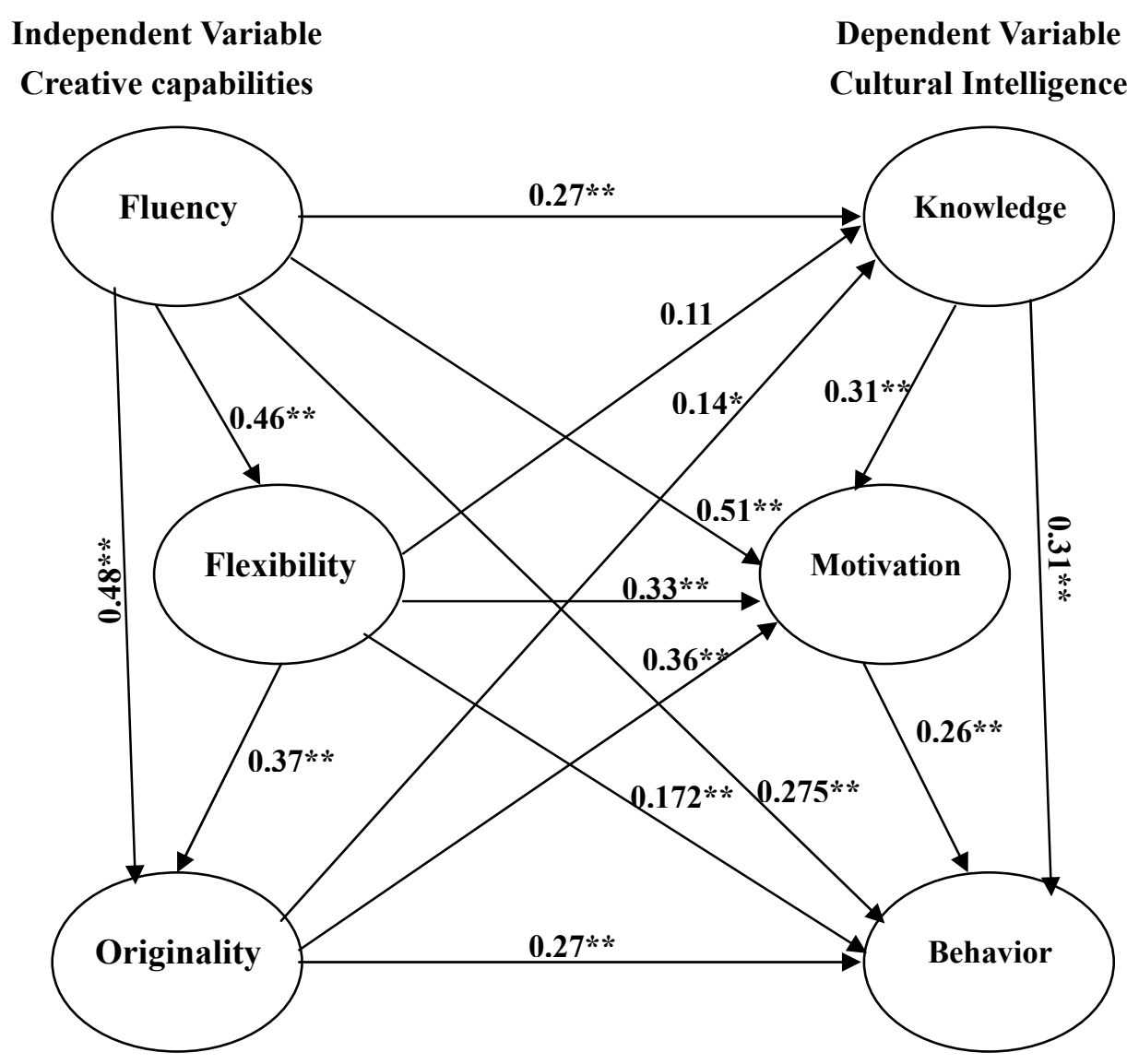

Figure 1.Study variables 
The researchers used a set of statistical methods, including: recurrences to describe the study sample distribution according to their personal characteristics. Also, the arithmetic mean and standard deviation were used to show the extent of concentration and dispersion of the values of the dimensions of the study variables on and away from their arithmetic mean. Furthermore, Pearson correlation coefficient was used to indicate the nature of the relationship between the dimensions of the study variables specified in its hypotheses.

\section{Results}

Table 2 refers to the findings of the descriptive statistical analysis of the statements constituting the two variables of the study which showed the high level of the availability of fluency as the first dimension of the creative capability, where the workers in the study sample responded to the total statements in this respect by "strongly agree" at a value of (4.15).In regard of flexibility, the workers responded to the statements constituting it by a little lesser than the above at "strongly agree" at an arithmetic mean of (4.01). Originality got a lesser rate at an arithmetic mean of (3.87) responding with "agree".

Moreover, regarding the cultural intelligence, values of the arithmetic mean of cognition amounted to (3.87) responding with "agree". As for motivation and behavior, the responses of the workers were by "strongly agree" at an arithmetic mean of (4.07) for motivation and (4.05) for behavior.

Table 2.Mean and standard deviation for the statements of the study two variables dimensions

\begin{tabular}{lllll}
\hline Variables & Items & Alpha & Mean & Std. \\
\hline Fluency & 5 & 0.83 & 4.15 & 0.51 \\
Flexibility & 5 & 0.75 & 4.01 & 0.45 \\
Originality & 5 & 0.73 & 3.87 & 0.48 \\
Knowledge & 6 & 0.74 & 3.78 & 0.45 \\
Motivation & 5 & 0.81 & 4.07 & 0.54 \\
Behavior & 5 & 0.75 & 4.05 & 0.45 \\
\hline
\end{tabular}

For the hypothesis of the study, the researchers used Pearson's correlation coefficient. Findings of this analysis are included in Table 3.

H01: No significant relationship among the creative capabilities constituents of the 5-star hotels workers in the city of Amman, (fluency, flexibility and originality).

Correlation analysis results showed that there was a significant relationship between the three dimensions that comprise the creative capability of workers, namely: fluency, flexibility and originality, as there is significant direct correlation between fluency and flexibility, where the value of the correlation coefficient between fluency and flexibility was at $(0.46)$ and the significant level was $(0.00)$. This means that the non-reluctance of workers to change their opinions once they are convinced that they are wrong, their understanding of others' views and their interest in knowing the opposing opinions to theirs to benefit from increasing their abilities to propose rapid solutions to work problems and to offer rapid initiative to confront contingent work circumstances. As for the relationship between fluency and originality, it was also positive and significant as the value of the correlation coefficient reached (0.48) and at a significant degree of $(0.00)$. This means that the fluency of workers needs them to devise new ideas. That is due to the fact that the more the workers feel they are far from recurring ideas for various problems and feeling bored and their desire to provide new ideas, the more this will help them in proposing multiple and fast solutions. It was also evident that there existed a significant positive relationship between originality and flexibility at a correlation value of $(0.37)$. In other words, the workers who are open-minded towards others' opinions and are able to change their opinions once they are convinced of others' viewpoints will be able to continuously generate new ideas and avoid recurrence. In the light of test's outcomes, the first null hypothesis of the study cannot be accepted.

H02: No significant relationship between the elements of the cultural intelligence of the workers in 5-star hotels in the city of Amman (motivation, cognition and behavior).

The findings of the correlation coefficient analysis showed the existence of a positive significant relationship between the dimensions comprising the cultural intelligence, namely: cognition, motivation and behavior, where the value of the correlation coefficient between cognition and motivation reached (0.31) at a significant level of $(0.00)$. This means that the workers' acquaintance with the prevailing regulations, laws, traditions and customs in the various cultures makes them more confident in interacting with such individuals as well as they will be more 
enjoying and more willing to do so. Further, the knowledge the workers have given them sufficient ground to take the initiative to interact with individuals of other cultures as it will enable them to change their verbal and non-verbal behavior where the value of the correlation coefficient between cognition and behavior reached $(0.31)$ at a significant level of $(0.00)$. Additionally, the relationship between motivation and behavior was also positive and significant. Its correlation coefficient value reached $(0.26)$ at a significant level of $(0.00)$. That is to say the workers' enjoyment in interacting with the others, their confidence in their abilities and their willingness to deal with the individuals of other cultures will assist them positively to adapt with them by using their language or dialect and to control the tone of their speaking with them.

H03: No significant relationship between fluency in the workers' thinking and the components of their cultural intelligence (cognition, motivation and behavior).

The findings of the correlation coefficient analysis in Table 3 implies the existence of a significant positive relationship between fluency as one of the dimensions of the creative capability of the workers with all three dimensions of the cultural intelligence, namely: cognition, motivation and behavior where the value of the correlation coefficient of the relationship between fluency and each of cognition and behavior reached $(0.27)$ at a significant value of (0.00). However, the value of the correlation coefficient between fluency and motivation was at (0.51). This means that the workers' capability to propose rapid solutions and provide rapid multiple creative ideas increases as their knowledge of economic systems, language, values, customs, traditions and arts of others from other cultures increases. Moreover, their fluency increases as the extent of their enjoyment, confidence and capability to accommodate with the cultures of others increases. It is also the same in regard of their capabilities to change their verbal and non-verbal behavior in their interaction with other individuals of different cultures. In the light of outcomes of correlation analysis test, it is impossible to accept the third null hypothesis.

H04: No significant relationship between flexibility in the workers' thinking and the components of their cultural intelligence (cognition, motivation and behavior).

The findings of the correlation coefficient analysis implies the existence of difference in the outcomes of the relationship test between flexibility as one of the dimensions of the workers' creative capability and the dimensions of the cultural intelligence, as it was shown that a significant positive relationship existed between flexibility on the one hand and motivation and behavior on the other at a correlation value of $(0.33)$ for motivation and (0.17) for behavior . Hence, the non-reluctance of the workers to change their opinions once they are convinced that they are wrong, and their acceptance of the others' views make them more enjoying and confident of their potentials to interact with others of different cultures. In regard of the relationship between flexibility and cognition, it did not yield any significant statistical indication, as the value of the correlation coefficient reached (0.11) at a significant value of (0.08). This means that the workers' flexibility has nothing to do with their awareness of the language, customs and traditions of individuals of other cultures. Consequently, based on the outcomes of the correlation analysis, it is impossible to accept the fourth null hypothesis.

H05: No significant relationship between originality in the workers' thinking and the components of their cultural intelligence (cognition, motivation and behavior).

The findings of the correlation coefficient analysis in Table 3 showed the existence of a significant positive relationship between originality as one of the workers' creative capability dimensions and the three dimensions of cultural intelligence, namely: cognition, motivation and behavior as the value of the correlation coefficient between originality and cognition amounted to $(0.14)$ at a significant level of $(0.02)$. That is to say, the more original the workers' thoughts are the more their knowledge increases. The same can be said about the relationship between originality and motivation as the value of the correlation coefficient reached $(0.36)$ at a significant level of (0.00). Thus, as long as the workers' thoughts are creative and new, their enjoyment and confidence in interacting with individuals of other cultures will increase. This was also the same case with the relationship between originality and behavior which reached $(0.27)$ at a significant value of $(0.00)$. Such outcomes lead to excluding the possibility of accepting the fifth null hypothesis. 
Table 3.Correlation between the dimensions of the creative capabilities and cultural intelligence

\begin{tabular}{|c|c|c|c|c|c|c|c|}
\hline Variables & & Fluency & Flexibility & Originality & Knowledge & motivation & Behavior \\
\hline \multirow[t]{3}{*}{ Fluency } & Pearson Correlation & & & & & & \\
\hline & Sig. (2-tailed) & 1 & & & & & \\
\hline & $\mathrm{N}$ & & & & & & \\
\hline \multirow[t]{3}{*}{ Flexibility } & Pearson Correlation & $.46^{* *}$ & & & & & \\
\hline & Sig. (2-tailed) & .00 & 1 & & & & \\
\hline & $\mathrm{N}$ & 258 & & & & & \\
\hline \multirow[t]{3}{*}{ Originality } & Pearson Correlation & $.48^{* *}$ & $.37^{* *}$ & & & & \\
\hline & Sig. (2-tailed) & .00 & .00 & 1 & & & \\
\hline & $\mathrm{N}$ & 258 & 258 & & & & \\
\hline \multirow[t]{3}{*}{ Knowledge } & Pearson Correlation & $.27^{* *}$ & .11 & $.14^{*}$ & & & \\
\hline & Sig. (2-tailed) & .00 & .08 & .02 & 1 & & \\
\hline & $\mathrm{N}$ & 258 & 258 & 258 & & & \\
\hline \multirow[t]{3}{*}{ Motivation } & Pearson Correlation & $.51^{* *}$ & $.33^{* *}$ & $.36^{* *}$ & $.31^{* *}$ & & \\
\hline & Sig. (2-tailed) & .00 & .00 & .00 & .00 & 1 & \\
\hline & $\mathrm{N}$ & 258 & 258 & 258 & 258 & & \\
\hline \multirow[t]{3}{*}{ Behavior } & Pearson Correlation & $.27^{* *}$ & $.17^{* *}$ & $.27^{* *}$ & $.31^{* *}$ & $.26^{* *}$ & \\
\hline & Sig. (2-tailed) & .00 & .005 & .00 & .00 & .00 & 1 \\
\hline & $\mathrm{N}$ & 258 & 258 & 258 & 258 & 258 & \\
\hline
\end{tabular}

**. Correlation is significant at the 0.01 level (2-tailed).

*. Correlation is significant at the 0.05 level (2-tailed).

\section{Discussion}

1) Workers in 5-star hotels functioning in the city of Amman are characterized by the high level of their creative capabilities as the outcomes of the descriptive statistical analysis of the dimensions of this variable showed the availability of high level fluency among the workers and a lesser degree of flexibility and originality respectively. In other words, the workers possess high capabilities in proposing of rapid and multiple solutions for work problems they confront. They take initiatives and never hesitate in expressing their thoughts and formulate them in appropriate words that fit various situations. In addition, their dealing with customers of different cultures makes them more flexible in changing their behaviour as they also possess the ability to listen to the opposite opinion and to change their viewpoints. For all that said, they find themselves in constant search of new non- recurrent solutions to face problems.

2) The existence of high levels of cultural intelligence dimensions which the workers in these hotels enjoy. On top of these dimensions is motivation, but lesser levels for behaviour and cognition. This means that the fact that the workers enjoy interaction and are confident of their capabilities to adapt with individuals of other cultures along with their willingness to build social relationships with them enables them not to hesitate in changing their verbal and non-verbal behaviour during their dealings with such individuals which will be assisted by their acquisition of sufficient knowledge of the languages, values, customs, traditions and verbal and non-verbal acts of individuals of other cultures.

3) The existence of a significant positive relationship between the three dimensions of creative capabilities: fluency, flexibility and originality at close levels. The strongest of such relationships was between fluency and originality. That is to say the workers' ability to offer multiple and diversified ideas as a solution of one problem will distance them from feeling bored due to non-recurrence of work. The speedy reaching of original ideas and the multiplicity of such ideas will enable workers to move rapidly to solutions they are capable of reaching.

4) The existence of a significant positive relationship between the dimensions of the workers' cultural intelligence, namely: cognition, motivation and behaviour at close levels, as workers do not hesitate to change their verbal and non-verbal behaviour due to their knowledge of languages, regulations, laws, customs and traditions of individuals of other cultures. This knowledge will motivate them and gives them enjoyment in interacting with such people.

5) The existence of a significant positive relationship between fluency as one of the creative capability dimensions and the three dimensions of the cultural intelligence: cognition, motivation and behaviour. This means that the workers' feelings that they are able to propose solutions to work problems rapidly and are capable 
of offering multiple ideas and are able to express their ideas are all obviously linked with their awareness and knowledge of the customs and habits of others.Further, this capability will make them more self-confident and motivates them to interact with others. Confidence that is built on awareness is what drives them to be non-hesitant in positive verbal and non-verbal interaction.

6) The existence of a significant positive relationship between flexibility on the one hand and motivation and behaviour on the other. In other words, the workers' interest in acquaintance with others' viewpoints and their non-reluctance to change their views will make them more enjoying and confident when they interact with others of other cultures. This confidence will be reflected in verbal and non-verbal positive interaction with them. As for the relationship between flexibility and cognition, it was non-significant.

7) The existence of a significant positive relationship between originality on the one hand and cognition, motivation and behaviour on the other. The strongest of such relationships was between originality and motivation, as once the workers enjoy interaction with individuals of other cultures they will be enabled to generate new ideas and convey them to the others and distance themselves from recurrence. In addition, new ideas are transferred to actual acts, such as the way of speaking, facial features and voice tone.

\section{Recommendations}

In the light of the findings reached by the study, the researchers can provide the following recommendations:

1) It is absolutely necessary for the managements of 5-star hotels functioning in the city of Amman to increase the knowledge of their employees and workers, especially in regard of knowledge about arts and handicrafts of other cultures. This can be done by presenting documentaries to them which represent part of customers' cultures that frequent these hotels the most.

2) Increase the knowledge of workers in respect of customs, traditions and social relations of customers who deal with these hotels the most. This can be realized through organizing and holding of forums and meetings in order to increase their awareness of various cultures. It also can be done by organizing visits to the countries which the hotel's customers form the highest rate of their visitors within the framework of the hotel's incentive system for workers.

3) Increase workers' knowledge in regard of non-verbal behaviour, such as the use of hands and eyes as well as smiling when dealing with individuals of other cultures. The researchers believe that this can be realized through training courses to be organized by the managements of such hotels, provided that the trainers should be well-versed with the aspects of non-verbal interaction with customers of other cultures.

4) Hotel managements should allocate a part of their incentive system to go in line with workers' encouragement in their pursuit to increase their knowledge of laws and economic systems regarding their customers of other cultures.

\section{References}

Ahn, M., \& Ettner, L. (2013). Cultural intelligence (CQ) in MBA curricula. Multicultural Education \& Technology Journal, 7(1), 4-16. http://dx.doi.org/10.1108/17504971311312591

Alias, A. (2011). Cultural intelligence and its social tolerance: An empirical study on the elementary school principals in educational Azizia. Journal of Supervision Educational, 1(2), 6-12.

Alkaisi, A., \& Altamimi, N. (2010). Creativity thinking of excellence and popular secondary students. Journal of Psychology Scientific, 19, 35-75.

Alnamla, Y. (2012). Saudi scholarship and cultural intelligence. Published doctoral thesis, King Fahd National Library, Riyadh.

Altahir, S. (2005). Creativity thinking competence, Concepts and dimensions. Journal of Cultural Psychology, 61 .

Andriopoulos, C. (2001). Determinants of organizational creativity: A literature review. Management Decision, 39(10), 834-840. http://dx.doi.org/10.1108/00251740110402328

Cheng, H. (2014). The effect of social embeddedness on bloggers' creativity. Online Information Review, 38(3), 399-416. http://dx.doi.org/10.1108/OIR-06-2013-0144

Fakhr-Alden, H. (2011). The effect of culture intelligence on employee performance in international hospitality industries: A case from the hotel sector Egypt. International Journal of Business and Public Administration, $8(2), 2-9$. 
Granot, E. (2011). Creative managers and managing creativity: A hermeneutic exploration.American Journal of Business, 26(2), 161-182. http://dx.doi.org/10.1108/19355181111174534

Guilford, J. (1950). Creativity. American Psychologist, 5, 444-454. http://dx.doi.org/10.1037/h0063487

Gupta, B., Singh, D., Jandhyala, K., \& Bhatt, S. (2013). Self-Monitoring, Cultural Training and Prior International Work Experience as Predictors of Cultural Intelligence-A Study of Indian Expatriates. Organizations and Markets in Emerging Economies, 4(1), 56-71.

Hansen, J. (2012). Cultural intelligence in cross-cultural selling: propositions and directions for future research. Journal of Personal Selling and Sales Management, 1(3), 243-245.

Hironymi, A. (2013). Creativity from a systems perspective: Bridging theory and practice. Kybemetes, 42(9/10), 1413-1423.

Jellab, I. (2011). The relationship between emotional intelligence and cultural intelligence: Analysis study of the views of a sample of teachers in the faculty of education, University of Qadisiya. Journal of Qadisiyah Management and Economic Sciences, 13(4), 8-19.

Johnson, R., \& Buko, S. (2013). Cultural Intelligence Scale (CQS): Testing Cross-cultural Transferability of CQS in Ukraine. Studies of Changing Societies: Comparative and Interdisciplinary Focus, 4(10), 51-67.

Kanten, P. (2014).The effect of cultural intelligence on competencies and customer-oriented behavior s. Istanbul University Journal of the School of Business, 43(1), 100-119.

Martens, Y. (2011). Creative workplace: instrumental and symbolic support for creativity. Facilities, 29(1/2), 63-79. http://dx.doi.org/10.1108/02632771111101331

Mazur, B. (2010). The effect of cultural diversity in organizational practice. Journal of International Management, 2(2), 5-15.

Moorhead, G., \& Griffin, R. (2000). Organizational Behavior (1st ed., pp. 104-105).

Nafei, W. (2012). The Impact of cultural intelligence on employee job performance: An empirical study on King Abdel-Aziz hospital in Al-Taif governorate, K.S.A. International Journal of Business and Management, 8(1), 26-43. http://dx.doi.org/10.5539/ijbm.v8n1p26

Ramalu, S., Che Rose, R., Kumar, N., \& Uli, J. (2010). Doing Business in Global Arena: An Examination of the Relationship between Cultural Intelligence and Cross-Cultural Adjustment. Asian Academy of Management Journal, 5(1), 79-97.

Rockstuhl, T., Seiler, S., Ang, S., Van Dyne, L., \& Annen, H. (2011). Beyond General Intelligence (IQ) and Emotional Intelligence (EQ): The Role of Cultural Intelligence (CQ) on Cross-Border Leadership Effectiveness in a Globalized World. Journal of Social Issues, 67(4), 825-840. http://dx.doi.org/10.1111/j.1540-4560.2011.01730.x

Sekaran, U. (2006). Research Methods for Business: A Skill Building Approach (4th ed.). John Wiley and Sons, (Asia) Pte Ltd. Singapore.

Shalley, C., Zhou, J., \& Oldham, G. (2004). The effects of personal and contextual characteristics on creativity: where should we go from here? Journal of Management, 30(6), 933-958. http://dx.doi.org/10.1016/j.jm.2004.06.007

Torrance, E. (1966). Torrance Test of Creative Thinking Personal. Education company, Mass Achuseell, U. S. A.

Van Dyne, L., Ang, S., Yee Ng, K., Rockstuhl, T., Ling Tan, M., \& Koh, C. (2012). Sub Dimensions of the Four Factor Model of Cultural Intelligence: Expanding the Conceptualization and Measurement of Cultural Intelligence. Journal of Social and Personality Psychology, 6(4), 295-313.

West, M. (2002).Sparkling fountains or stagnant ponds: an integrative model of creativity and innovation implementation in work groups. Applied Psychology, 51(3), 355-387. http://dx.doi.org/10.1111/1464-0597.00951

Wu, Ch., Lee, Ch., \& Tsai, L. (2012). Influence of creativity and knowledge sharing on performance. Journal of Technology Management in China, 7(1), 64-77. http://dx.doi.org/10.1108/17468771211207358

Zhao, F., Deng, L., \& Kemp, L. (2013). Interrelationships between cultural intelligence dimensions and the role of intrapersonal intelligence. Journal of General Management, 38(3), 3-24. 


\section{Copyrights}

Copyright for this article is retained by the author(s), with first publication rights granted to the journal.

This is an open-access article distributed under the terms and conditions of the Creative Commons Attribution license (http://creativecommons.org/licenses/by/3.0/). 